\title{
UTERINE ARTERY DOPPLER IN THE PREDICTION OF PIH AND IUGR
}

\author{
P. Muthu Prabha1, Divya Bharathi² \\ ${ }_{1}^{1}$ Senior Assistant, Professor and Registrar, Department of Obstetrics \& Gynaecology, Tirunelveli Medical College Hospital. \\ ${ }^{2}$ Senior Resident, Department of Obstetrics \& Gynaecology, Tirunelveli Medical College Hospital.
}

\section{ABSTRACT}

\section{AIM}

Aim of this clinical study is to find out the sensitivity of uterine artery Doppler in prediction of hypertensive disorder in pregnancy and intrauterine growth restriction at 20-22 weeks of gestation, thereby to follow up the at risk patients and to improve perinatal outcome.

\section{MATERIALS AND METHODS}

The study was conducted at Tirunelveli Medical College Hospital from September 2013 to August 2014 in the Department of Obstetrics and Gynaecology and in the Department of Radiology.

About 200 antenatal mothers were selected and they were separated as (i) High risk (Group-I), (ii) Low risk (Group-II). High risk cases include 100 antenatal mothers with previous history of hypertension, FGR or IUD at 20-22 weeks of gestation. Low risk cases include 100 antenatal mothers (primi/multipara) at 20-22 weeks with no prior history of hypertension, FGR or IUD.

\section{OBSERVATION}

In Group-I two cases (6.1\%) had HTD, 15 cases (45.4\%) had FGR in cases with persistence of bilateral notch in uterine artery. In Group I one case $(20.0 \%)$ had HTD, 3 cases $(60.0 \%)$ had FGR in cases with persistence of unilateral notch in uterine artery. In Group I four cases (6.7\%) had HTD and 4 cases (6.7\%) had FGR in case of absent notch in uterine artery. In Group II one case (8.3\%) had HTD, 2 cases (16.7\%) had FGR in presence of bilateral notch in uterine artery. In Group II, no cases reported to have HT in both unilateral and absent notches; one case (8.3\%) had FGR in case of persistence of unilateral notch and no case had FGR in case of absent notch. Bilateral notch persistence was associated with severe form of HTD and FGR compared to unilateral notch in uterine artery. In this study in Group I in case of bilateral notch $6.1 \%$ had gestational HT, 18.2\% had mild preeclampsia, 30.3\% had severe preeclampsia. In case of unilateral notch $20.0 \%$ had gestational HT, $20.0 \%$ had mild preeclampsia, $20.0 \%$ had severe preeclampsia. In Group II in cases of persistence of bilateral notch $8.3 \%$ had gestational HT, $8.3 \%$ had mild preeclampsia, $8.3 \%$ had severe preeclampsia. In case of unilateral notch $16.7 \%$ had mild preeclampsia.

\section{CONCLUSION}

Though preeclampsia is not a preventable disease, early detection helps in increased foetal surveillance and timely interventions. From the study it is concluded that in Group I (High risk) in cases of bilateral notches there is increased risk of preeclampsia, FGR, and abnormal perinatal outcome compared to cases with unilateral notches and absent notch in uterine artery. In both Group I and Group II, bilateral diastolic notch was associated with poor prognosis. It is better to do Uterine Artery Doppler study along with target scan at 20-22 weeks of gestation, thereby both anomalies of foetus and risk of preeclampsia; FGR can be predicted in the same visit. Cost of the test is the drawback in doing the test in government hospital. It is concluded from the study that in Group I and II, those cases with bilateral notch require more foetal surveillance and timely intervention compared to unilateral and absent notch. Cases with absent notches require only routine checkup and not frequent checkup.

Abbreviation:

HTD : Hypertensive Disease.

FGR : Foetal Growth Restriction.

IUD : Intrauterine Death.

\section{KEYWORDS}

HTD, FGR, Doppler Velocimetry.

HOW TO CITE THIS ARTICLE: Prabha PM, Bharathi D. Uterine artery Doppler in the prediction of PIH and IUGR. J. Evolution Med. Dent. Sci. 2016;5(64):4542-4546, DOI: 10.14260/jemds/2016/1037

\section{INTRODUCTION}

The primary aim of antenatal care is to achieve at the end of pregnancy a healthy mother and a healthy baby.

Recently, there have been many modern investigative and treatment modalities to provide good health care. Despite

Financial or Other, Competing Interest: None.

Submission 12-04-2016, Peer Review 07-05-2016,

Acceptance 12-05-2016, Published 10-08-2016.

Corresponding Author:

Dr. P. Muthu Prabha,

Senior Assistant Professor and Registrar,

Department of Obstetrics \& Gynaecology

Tirunelveli Medical College Hospital.

E-mail: drmuthuprabha85@yahoo.com

DOI: $10.14260 /$ jemds/2016/1037 advances in antenatal care, hypertensive disorder in pregnancy contributes to increased maternal morbidity and mortality and thereby accounts for increased perinatal morbidity and mortality.

Major cause of maternal mortality according to 2001-2003 SRS survey are Haemorrhage (38\%), sepsis (11\%), hypertension (5\%), obstructed labour $(5 \%)$, abortion $(8 \%)$ and other conditions (34\%). As far as hypertension is considered, the main pathophysiology in preeclampsia and foetal growth restriction is impaired uteroplacental and foetoplacental circulation respectively.

Colour Doppler ultrasound of uterine artery at 20-22 weeks of gestation showing persistent diastolic notch helps in 
predicting hypertensive disorder in pregnancy and intrauterine growth restriction.

Normally, the early diastolic notch persists till 22 weeks, after which there will be disappearance of diastolic notch. Persistence of diastolic notch beyond 22 weeks indicates defective placentation. The study is conducted to predict hypertensive disorder in pregnancy and intrauterine growth restriction by using uterine artery Doppler and thereby to follow-up the risk patients and to reduce both maternal and perinatal morbidity and mortality.

Foetal Growth Restriction (FGR)

Foetus with estimated weight below the $10^{\text {th }}$ percentile for a given gestational age due to a pathologic process that inhibits intrinsic growth potential is called foetal growth restriction (ACOG-2000).

\section{Incidence}

$10 \%$ in developing countries, $5-7 \%$ in developed countries.

\section{Risk Factors for FGR}

- Extremes of reproductive age (Younger than 16 yrs. and older than 35 yrs.).

- Poor maternal weight gain.

- Poor pre-pregnancy weight.

- Severe malnutrition.

- Low socio-economic status.

- Maternal Medical Conditions.

- Hypertension.

- Renal disease.

- Diabetes (With microvascular disease).

- Cyanotic heart disease.

- Antiphospholipid syndrome.

- Collagen vascular disease.

- Haemoglobinopathy.

- Chromosomal anomalies.

- Structural anomalies.

- Primary placental disease.

- Infections.

- Exposure to teratogens.

\section{AETIOPATHOGENESIS FACTORS IN FGR Placental Causes}

- Incomplete trophoblastic invasion of the spiral arteries in the placental bed.

- Accelerated atherosclerosis of spiral arteries.

- Increased number of syncytial knots, obliteration of arteries in tertiary stem villi, stromal fibrosis.

- Placental infarction and thrombosis due to factor V mutation and antiphospholipid syndrome.

- Endothelial dysfunctions due to decreased VEGF and PDGF and soluble endoglin decrease nitric oxide department vasodilation.

\section{Maternal Causes}

- Chronic hypertension

- Chronic renal disease

- Diabetes

- Preeclampsia

- Grade 3, 4 heart disease

- Smoking, alcohol, tobacco chewing

- SLE

- Fever, sickle cell anaemia, malnutrition

\section{ANTENATAL DIAGNOSIS OF FGR}

- Physical Examination

Discordance between gestational age and symphysio fundal height $>4 \mathrm{~cm} .^{1}$

- USG Parameters

- Biparietal diameter, Head circumference, Abdominal circumference, Femur length, Estimated foetal weight.

- Women with negative uterine Doppler screening are at low risk of FGR (Negative predictive value of $97 \%-99 \%)^{1}$ and can be followed as normal pregnancies.

- Uterine Artery Doppler Screening.

Presence of bilateral diastolic notch in uterine arteries is the predictor of FGR.

Diagnosis depends on

- Correct estimation of gestational age, preferably in the 1 st trimester.

- Gestational age based on LMP using Naegele's rule is uncertain in $20 \%-40 \%$ of cases.

- Gestational age is best established in 1st trimester using CRL measurement. Predictive error of EDD based on CRL is 7 days.

Integrated foetal testing:

Baschat (2003)2 has suggested multiple testing to monitor FGR

- Periodic foetal biometry.

- AFI

- Multi-vessel arterial and venous Doppler.

- Biophysical Profile (BPP).

- Foetal heart rate monitoring (CTG).

- Foetal movement counting.

\section{USG Parameters}

- HC/AC Ratio.

- It compares the most preserved organ (brain) with the most affected organ (liver).

- $\mathrm{HC} / \mathrm{AC}$ is normal in symmetric FGR.

- $\mathrm{HC} / \mathrm{AC}$ is increased in asymmetric FGR. $>95$ percentile for gestational age.

- Normally, HC/AC ratio is $>1$ up to 36 weeks. After 36 weeks, the value of $\mathrm{HC} / \mathrm{AC}$ ratio is $<1$.

- Head circumference is measured at the level of thalami. Abdominal circumference is measured at the level of bifurcation of hepatic vein in the center of foetal liver.

\section{Amniotic Fluid Volume (AFI)}

AFI is important both in diagnosis and prognosis of FGR.

\section{Growth Charts}

Serial ultrasounds at intervals of two to four weeks for evaluation of foetal growth with the use of standardised growth curves demonstrate growth velocity.

\section{Umbilical Artery Doppler}

Umbilical artery Doppler helps to differentiate a normal small for gestational age foetus from the growth restricted foetus. Doppler Study in Uteroplacental Insufficiency.

Doppler USG is used recently for assessing uteroplacental insufficiency, thereby preeclampsia and FGR is detected earlier. It was first demonstrated by Campbell in 1983. The 
feasibility of its foetal application was demonstrated by Fitzgerald and Drumm.

The uterine artery Doppler is measured at a point just distal to the crossover with the iliac arteries before uterine artery divides into arcuate arteries.

\section{Normal Uterine Artery Doppler Form}

In non-pregnant women, there is a steep systolic flow and an early diastolic notch showing high vascular resistance. At 4 weeks after implantation, well-defined, low-resistant vessels are seen in future placenta. In second trimester uncoiling of uterine and spiral arteries occurs, so that low resistance occurs. In later trimester, there is a gradual removal of notch and increase in diastolic flow and decrease in resistance index. Resistance index was used as screening tool, but it has low sensitivity.

Bollar et al demonstrated that presence of notch in the artery homolateral to the placenta was associated with poor prognosis.

Michael S. Kraner et al mentioned environmental factors like stress, low socioeconomic status and overcrowded housing increase cortisol levels higher in maternal and foetal circulation and that leads to impaired placentation.

DIGITAT (Disproportionate Intrauterine Growth Intervention Trial At Term) study showed no difference in perinatal outcome, if after 36 weeks delivery was by induction of labour or by expectant management (Boers, 2010). ${ }^{3}$

\section{Indices Used in Doppler}

- Arterial system

- $\mathrm{S} / \mathrm{D}$ ratio = systolic peak velocity/end diastolic velocity.

- $\quad \mathrm{S}-\mathrm{D} / \mathrm{S}=$ Resistance index.

- $\quad$ S-D/Mean frequency shift = Pulsatility Index

\section{MATERIALS AND METHODS}

The clinical study was conducted at Tirunelveli Medical College Hospital from September 2013 to August 2014 in the Department of Obstetrics and Gynaecology and in the Department of Radiology.

\section{Selection of Cases}

About 200 antenatal mothers were selected and they were separated as, (i) High risk (Group I), (ii) Low risk (Group II). High risk cases include 100 antenatal mothers with previous history of hypertension, FGR, IUD at 20-22 weeks of gestation. Low risk cases include 100 antenatal mothers (primi/multipara) at 20-22 weeks with no prior history of hypertension, FGR or IUD.

\section{Exclusion Criteria}

Multiple gestations, Antenatal mother with cardiac diseases, DM, SLE, chronic hypertension and epilepsy.

\section{METHOD OF STUDY}

All antenatal mothers were registered in Antenatal OPD. A detailed history elicited and then examination done. After getting consent, Doppler study done at 20-22 weeks of gestation. The Doppler character studied for prediction of preeclampsia and FGR was bilateral diastolic notch.

\section{Doppler Study Method}

Antenatal mother is placed in a supine and slightly left lateral position to prevent supine hypotension. The frequency of
Doppler used is 3.5-5 MHZ. Doppler measurement is done at a point just distal to the crossover with the iliac artery before uterine artery divides into arcuate arteries.

\section{RESULTS AND ANALYSIS}

Computer statistical analysis was used to analyse the statistics. Comparison of data was done using chi-square test. Multivariate analysis of data was done. Validity of the tests was evaluated by calculating sensitivity, specificity, positive and negative predictive values, likelihood ratio for positive and negative test with $95 \%$ confidence interval.

In Group I (High risk) 100 cases and in Group II (Low risk) 100 cases were selected and prospectively followed up; 3 cases in Group I and 2 cases in Group II were lost to follow up. The selected cases had uterine artery evaluation between 20-22 weeks gestation and followed up for development of hypertensive disorders, foetal growth restriction, gestational age at delivery, mode of delivery and perinatal outcome.

\section{Table-I Notch Distribution}

\begin{tabular}{|l|c|l|c|c|}
\hline & \multicolumn{2}{|c|}{ Group-I } & \multicolumn{2}{c|}{ Group-II } \\
\hline \multicolumn{1}{|c|}{ Notch } & Count & $\mathbf{\%}$ & Count & $\mathbf{\%}$ \\
\hline Absent & 59 & 60.82 & 80 & 81.63 \\
\hline Bilateral & 33 & 34.02 & 12 & 12.24 \\
\hline Unilateral & 5 & 5.15 & 6 & 6.12 \\
\hline Total & $\mathbf{9 7}$ & $\mathbf{1 0 0}$ & $\mathbf{9 8}$ & $\mathbf{1 0 0}$ \\
\hline
\end{tabular}

Conclusion: In Group I bilateral notch was present in 33 cases $(34.02 \%)$ and unilateral notch was present in 5 cases $(5.15 \%)$. In Group II, bilateral notch was present in 12 cases (12.24\%) and unilateral notch was present in 6 cases $(6.12 \%)$.

Table-II Notch and FGR

\begin{tabular}{|c|c|c|c|c|c|c|}
\hline & \multicolumn{3}{|c|}{ Group-I } & \multicolumn{3}{c|}{ Group-II } \\
\hline \multirow{2}{*}{ Notch } & \multicolumn{2}{|c|}{ FGR } & \multirow{2}{*}{ Total } & \multicolumn{2}{c|}{ FGR } & \multirow{2}{*}{ Total } \\
\cline { 2 - 3 } & Present & Absent & & Present & Absent & \\
\hline Absent & 4 & 55 & 59 & 2 & 78 & 80 \\
\hline Bilateral & 15 & 18 & 33 & 3 & 9 & 12 \\
\hline $\begin{array}{c}\text { Uni- } \\
\text { lateral }\end{array}$ & 3 & 2 & 5 & 0 & 6 & 6 \\
\hline Total & $\mathbf{2 2}$ & $\mathbf{7 5}$ & $\mathbf{9 7}$ & $\mathbf{5}$ & $\mathbf{9 3}$ & $\mathbf{9 8}$ \\
\hline
\end{tabular}

Conclusion: Group I P $=<0.001$. $\mathrm{P}$ value of $<0.000$ indicates significant relationship between notch and FGR. Group II P = 0.092. $\mathrm{P}$ - value of 0.092 indicates significant relationship between notch and FGR.

Table-III Notch and HTD-FGR

\begin{tabular}{|c|c|c|c|c|c|c|}
\hline & \multicolumn{3}{|c|}{ Group-I } & \multicolumn{3}{c|}{ Group-II } \\
\hline \multirow{3}{*}{ Notch } & \multicolumn{2}{|c|}{ HTD-FGR } & \multirow{2}{*}{ Total } & \multicolumn{2}{c|}{ HTD-FGR } & \multirow{2}{*}{ Absent } \\
\cline { 2 - 3 } & Absent & Present & & Present & \\
\hline Absent & 58 & 1 & 59 & 80 & 0 & 80 \\
\hline Bilateral & 27 & 6 & 33 & 10 & 2 & 12 \\
\hline $\begin{array}{c}\text { Uni- } \\
\text { lateral }\end{array}$ & 4 & 1 & 5 & 5 & 1 & 6 \\
\hline Total & $\mathbf{8 9}$ & $\mathbf{8}$ & $\mathbf{9 7}$ & $\mathbf{9 5}$ & $\mathbf{3}$ & $\mathbf{9 8}$ \\
\hline
\end{tabular}

Conclusion: Group I P=0.022, P value of 0.022 indicates significant relationship between notch and HTD-FGR. Group IIP $=0.007, \mathrm{P}$ value of 0.007 indicate significant relationship between bilateral notch and HTD-FGR. 
Table-IV Notch and Perinatal Outcome

\begin{tabular}{|l|c|c|c|c|c|c|}
\hline & \multicolumn{3}{|c|}{ Group I } & \multicolumn{3}{c|}{ Group II } \\
\hline \multirow{3}{*}{ Notch } & \multicolumn{2}{|c|}{$\begin{array}{c}\text { Perinatal } \\
\text { Outcome }\end{array}$} & \multirow{2}{*}{ Total } & \multicolumn{2}{c|}{$\begin{array}{c}\text { Perinatal } \\
\text { Outcome }\end{array}$} & Total \\
\cline { 2 - 6 } & $\begin{array}{c}\text { Ab- } \\
\text { normal }\end{array}$ & Normal & & $\begin{array}{c}\text { Ab- } \\
\text { normal }\end{array}$ & Normal & \\
\hline Absent & 8 & 51 & 59 & 1 & 79 & 80 \\
\hline Bilateral & 17 & 16 & 33 & 5 & 7 & 12 \\
\hline Unilateral & 4 & 1 & 5 & 1 & 5 & 6 \\
\hline Total & 29 & 68 & 97 & 7 & 91 & 98 \\
\hline
\end{tabular}

\section{Conclusion:}

Group I P $=0.003$, P value of 0.003 (only at $5 \%$ ) indicates a significant relationship between notch and perinatal outcome. Abnormal perinatal outcome is associated with Unilateral and Bilateral notch.

Group II $\mathrm{P}=<0.001$, $\mathrm{P}$ value of $<0.001$ indicates significant (at 5\%) relationship between notch and perinatal outcome. Notch is associated with perinatal abnormality.

\section{DISCUSSION}

Doppler study application was made feasible first by Fitzgerald and Drumm. It is a non-invasive technique, which uses high frequency sound waves for investigation of blood flow.

- In Group I, 2 cases (6.1\%) had HTD; 15 cases (45.4\%) had FGR in cases with persistence of bilateral notch.

- In Group I, 1 case (20.0\%) had HTD, 3 cases (60.0\%) had FGR in the case with persistence of unilateral notch.

- In Group I, 4 cases (6.7\%) had HTD and 4 cases (6.7\%) had FGR in case of absent notch.

- In Group II, 1 case (8.3\%) had HTD; 2 cases (16.7\%) had FGR in presence of bilateral notch.

- In Group II, no cases reported to have HT in both unilateral and absent notches.

- One case (8.3\%) had FGR in case of persistence of unilateral notch and no case had FGR in case of absent notch.

- Bilateral notch persistence was associated with severe form of HTD and FGR compared to unilateral notch.

- Rofinas et al found persistence of diastolic notch in uterine artery with increased risk of HTD, FGR, caesarean delivery, preterm delivery and admission to NICU.

- According to NICE guideline, women with atleast one high and 2 moderate risk factors of preeclampsia should be given $75 \mathrm{mg}$ of Aspirin daily from 12 weeks of pregnancy till the delivery of the baby. ${ }^{4}$

- $\quad$ SOGC guidelines $(2008)^{7}$ suggest that women with mildmoderate HT and without co-morbid conditions should have antihypertensive to lower DBP to $80-105 \mathrm{mmHg}$. Hypertensive women with co-morbid conditions like DM, chronic HT and renal disease should have systolic BP 130$139 \mathrm{mmHg}$ and DBP of $80-89 \mathrm{mmHg}$.

- Campbell et al first demonstrated relationship between HTD, FGR, foetal distress, increased caesarean delivery and low APGAR score with persistent bilateral diastolic notch

- Deutinger et $\mathrm{al}^{5}$ found that early diastolic notch was associated with increased uteroplacental insufficiency.

- Pai found that in predicting HTD/FGR, persistent diastolic notch was a better parameter than resistant index. ${ }^{6}$

- Zimmermann et al studied the utility of uterine artery Doppler between 21-24 weeks in prediction of preeclampsia and FGR. Doppler was less informative in cases of low risk. In case of bilateral notch, there is increased risk of preeclampsia and FGR. In case of bilateral notch, preeclampsia and FGR was noted in 58.3\% compared to $8.3 \%$ in absent notch. ${ }^{7}$

- Flesicher et al conducted the study after 26 weeks and found that early diastolic notch was associated with increased caesarean rate, preeclampsia, FGR. foetal distress and admission to NICU.

- Thaler et al found diastolic notch as a better outcome than S/D ratio and Resistance Index (RI).

- Bower et al also found correlation between diastolic notch and HTD, FGR, foetal distress.

- In this study, in Group I, in case of bilateral notch, $6.1 \%$ had gestational HT, $18.2 \%$ had mild preeclampsia, $30.3 \%$ had severe preeclampsia.

- In case of unilateral notch, $20.0 \%$ had gestational HT, $20.0 \%$ had mild preeclampsia, $20.0 \%$ had severe preeclampsia.

- In Group II in cases of persistence of bilateral notch $8.3 \%$ had gestational HT, $8.3 \%$ had mild preeclampsia, $8.3 \%$ had severe preeclampsia.

- In case of unilateral notch, $16.7 \%$ had mild preeclampsia.

- Aristidou et al and Christopher Lees demonstrated persistent diastolic notches with increased risk of HT, FGR and low APGAR scores.

- In this study, preterm delivery was more common in High risk (Group I) cases.

- In Group I, 30.3\% had preterm delivery in case of bilateral notches and only $20.0 \%$ had preterm delivery in case of unilateral notches.

- The useful part of a test depends on negative predictive value. Negative predictive value of $100 \%$ in Group II (low risk) indicates that both HT/FGR will not be present.

\section{CONCLUSION}

- Though preeclampsia is not a preventable disease, early prediction helps in increased foetal surveillance and timely interventions.

- From the study it is concluded that in Group I and II, in case of bilateral notches there is increased risk of preeclampsia, FGR, preterm delivery and abnormal perinatal outcome compared to cases with unilateral notches and absent notches.

- In both Group I and Group II, bilateral diastolic notch was associated with poor prognosis.

- It is better to do Uterine Artery Doppler study along with target scan at 20-22 weeks of gestation, thereby both anomalies of foetus and risk of preeclampsia, FGR can be predicted in the same visit.

- Prediction value of Uterine Artery Doppler study is increased by doing the test along with serum beta HCG, PAPP-A and inhibin A.

- Cost of the test is the drawback in doing the test in government setup.

- From the study it is concluded that in Group I and II, those cases with bilateral notch require more foetal surveillance and timely intervention compared to unilateral and absent notch.

- Cases with absent notches require only routine checkup and not frequent checkups. 


\section{REFERENCES}

1. Harding K, Evans S, Newnham J. Screening for the small foetus: a study of the relative efficacies of ultrasound biometry and symphysio-fundal height. Aust NZJ Obstet Gynaecol 1995;35(2):160-4.

2. Baschat AA. Integrated foetal testing in growth restriction; combining multi-vessel Doppler and biophysical parameters. Ultrasound Obstet Gynecol 2003;21:1-8.

3. Boers KE, Vijgen SM, Bijlenga $D$, et al. Induction versus expectant monitoring for intrauterine growth restriction at term: randomised equivalence trial (DIGITAT). Brit Med J 2010;341:c7087.

4. National institute for health and clinical excellence. Hypertension in pregnancy. CG No: 107. London, national institute for health and clinical excellence 2010.
5. SOGC practice guideline No: 206 March. Diagnosis, evaluation and management of hypertensive disorders of pregnancy. J Obstet Gynecol Canada 2008;30(3).

6. Pai MV. Improved prediction of PIH and IUGR by two stage screening of uterine artery Doppler velocimetry. Ind J Med Ultrasound 2001;2:64-9.

7. Zimmermann P, Eirrio V, Kosjkinen J, et al. Doppler assessment of the uterine and uteroplacental circulation in the second trimester in pregnancies at high risk for preeclampsia and/or intrauterine growth retardation: comparison and correlation between different Doppler parameters. Ultrasound Obstet Gynecol 1997;9(5):330-8. 